\title{
EDITORIAL
}

\section{JNC 8: EVIDENCE-BASED GUIDELINE FOR THE MANAGEMENT OF HIGH BLOOD PRESSURE IN ADULTS IN 2014}

Hypertension remains one of the most important preventable contributors to disease and death. Abundant evidence from randomized controlled trials (RCTs) have shown benefit of antihypertensive drug treatment in reducing important health outcomes in persons with hypertension. ${ }^{\mathbf{1 - 3}}$ Clinical guidelines are at the intersection between research evidence and clinical actions that can improve patient outcomes.

The panel members appointed to the Eighth Joint National Committee (JNC 8) used rigorous evidencebased methods, developing evidence statements and recommendations for blood pressure $(\mathrm{BP})$ treatment based on a systematic review of the literature to meet user needs, especially the needs of the primary care clinician. This report is an executive summary of the evidence and is designed to provide clear recommendations for all clinicians. There are some major differences from the previous JNC report.

The panel members appointed to JNC 8 were selected from more than 400 nominees based on expertise in hypertension ( $n=14)$, primary care $(n=6)$, including geriatrics $(n=2)$, cardiology $(n=2)$, nephrology $(n=$ $3)$, nursing $(n=1)$, pharmacology $(n=2)$, clinical trials $(n=6)$, evidence-based medicine ( $n=3)$, epidemiology $(n=1)$, informatics $(n=4)$, and the development and implementation of clinical guidelines in systems of care $(\mathrm{n}=4)$.

Hypertension is the most common condition seen in primary care and leads to myocardial infarction, stroke, renal failure, and death if not detected early and treated appropriately. Patients want to be assured that blood pressure (BP) treatment will reduce their disease burden, while clinicians want guidance on hypertension management using the best scientific evidence. This report takes a rigorous, evidence-based approach to recommend treatment thresholds, goals, and medications in the management of hypertension in adults. Evidence was drawn from randomized controlled trials, which represent the gold standard for determining efficacy and effectiveness. Evidence quality and recommendations were graded based on their effect on important outcomes.
There is strong evidence to support treating hypertensive persons aged 60 years or older to a BP goal of less than $150 / 90 \mathrm{mmHg}$ and hypertensive persons 30 through 59 years of age to a diastolic goal of less than $90 \mathrm{mmHg}$; however, there is insufficient evidence in hypertensive persons younger than 60 years for a systolic goal, or in those younger than 30 years for a diastolic goal, so the panel recommends a BP of less than $140 / 90 \mathrm{mmHg}$ for those groups based on expert opinion. The same thresholds and goals are recommended for hypertensive adults with diabetes or non-diabetic chronic kidney disease (CKD) as for the general hypertensive population younger than 60 years. There is moderate evidence to support initiating drug treatment with an angiotensinconverting enzyme inhibitor, angiotensin receptor blocker, calcium channel blocker, or thiazide-type diuretic in the nonblack hypertensive population, including those with diabetes. In the black hypertensive population, including those with diabetes, a calcium channel blocker or thiazide-type diuretic is recommended as initial therapy. There is moderate evidence to support initial or add-on antihypertensive therapy with an angiotensinconverting enzyme inhibitor or angiotensin receptor blocker in persons with CKD to improve renal outcomes.

Although this guideline provides evidence-based recommendations for the management of high $\mathrm{BP}$ and should meet the clinical needs of most patients, these recommendations are not a substitute for clinical judgment, and decisions about care must carefully consider and incorporate the clinical characteristics and circumstances of each individual patient.

The world medical community was waiting for this new recommendation for more than 12 years.

There is clear difference from JNS 7 in many respects but in respect to methodology JNC 8 is more evidence based. In December 18, 2013 JNC8 report published in JAMA.

Professor Quazi Tarikul Islam

Editor in Chief

prof.tarik@gmail.com 


\section{References}

1. Staessen JA, Fagard R, Thijs L, et al; The Systolic Hypertension in Europe (Syst-Eur) Trial Investigators. Randomised double-blind comparison of placebo and active treatment for older patients with isolated systolic hypertension. Lancet. 1997; 350(9080): :757-764.

2. Beckett NS, Peters R, Fletcher AE, et al; HYVET Study Group. Treatment of hypertension in patients
80 years of age or older. N Engl J Med. 2008; 358(18):1887-1898.

3. SHEP Cooperative Research Group. Prevention of stroke by antihypertensive drug treatment in older persons with isolated systolic hypertension: final results of the Systolic Hypertension in the Elderly Program (SHEP). JAMA. 1991; 265(24): 3255- 3264.

4. JAMA. doi: 10.1001/jama.2013.284427; Published Online December 18, 2013 